\title{
EXPERIÊNCIAS de PROFESSORES, ENSINO de HISTÓRIA E O DESENVOLVIMENTO dO CONHECIMENTO HISTÓRICO
}

Teachers' Experiences, History Teaching And the DeVelopment of Historical Knowledge

\author{
Adriana Sobanki* \\ drisobanski@gmail.com \\ Rita de Cássia Santos** \\ professoraritadecassia@gmail.com
}

RESUMO: Discute teoricamente o papel do professor e de como ele utiliza o seu conhecimento do passado para se desenvolver enquanto professor-pesquisador. Apresenta discussões teóricas, a partir de aportes bibliográficos e empíricos sobre o desenvolvimento do professor pesquisador e do papel da sua experiência e do passado. Debate a formação deste profissional e como a perspectiva da Educação Histórica auxilia o desenvolvimento da consciência histórica de alunos, tendo como ponto de partida o reconhecimento de que o professor e suas experiências estão intrinsicamente ligados a um trabalho pedagógico bem desenvolvido. Apresenta resultado de trabalho empírico junto a professores da rede estadual de ensino do Paraná. Está ancorado, teoricamente, nas discussões apresentadas por Schmidt (2015), Barca (2012), Rüsen (2001, 2007 e 2012), Peter Seixas $(1994,1998)$ e Lowenthal $(1989,1998)$.

PALAVRAS CHAVE: Professores, Formação, Ensino de História.

ABSTRACT: Discuss, theoretically, the role of the teacher and how he uses his knowledge of the past to develop as a teacher -researcher. Presents theoretical discussions, based on bibliographical and empirical contributions on the development of the researcher's teacher and the role of his experience and his past, discussing the formation of this professional and how the perspective of Historical Education assists the development of the historical awareness of students, point of departure to the recognition that the teacher and his experiences are intrinsically linked to a welldeveloped pedagogical work. Also presents results of empirical work with teachers of the state education of Paraná. It is anchored theoretically in the discussions presented by Schmidt (2015), Barca (2012), Rüsen (2001, 2007 and 2012), Peter Seixas $(1994,1998)$ and Lowenthal $(1989,1998)$.

KEYWORDS: Teacher, Teacher Training, History teacher.

\section{Considerações sobre o professor e sua formação}

É inegável que as discussões sobre o papel dos professores sempre fazem parte de qualquer pesquisa referente à educação. Diversos estudos foram e são realizados procurando ora culpabilizar sua formação e atuação, ora buscando demonstrar a importância da formação e atuação desses profissionais sobre o processo de ensinoaprendizagem.

Para Arroyo (1991), a entrada no mundo capitalista foi a principal responsável pela divisão das funções existentes dentro da própria escola, sobretudo daquilo que chama de

\footnotetext{
* Doutora em Educação pela Universidade Federal do Paraná. Professora de História da Rede Estadual de Educação do Paraná.

** Doutora em Educação - Filosofia e História da Educação - pela Universidade Federal de Pelotas. Professora do Programa de Pós-Graduação da Universidade Tuiuti do Paraná.
} 
"nova cultura tecnológica". Essa característica fez com que a escola deixasse de cumprir sua função de formar os cidadãos adequadamente para o novo mercado de trabalho. Sua principal crítica, assim, passou a se assentar sobre o fato de que a divisão capitalista do trabalho separa, cada vez mais, o trabalho intelectual e o trabalho manual, deslocando o saber e qualificação do trabalhador.

Afirma ainda o autor que a cada divisão de tarefas percebe-se com mais clareza a expropriação do saber do trabalhador.

Como profissionais do educativo passamos a ver nesses processos uma história da expropriação do saber e da qualificação do trabalhador. A história da produção passou a ser uma história em torno do eixo: domínio do saber sobre o trabalho. Dependendo do grau desse domínio pelo trabalhador concluíamos pela capacidade formadora ou deformadora de cada fase dessa história. (ARROYO, 1991, p. 171)

Segundo Nóvoa (2002), essas características levam os professores a uma perda de prestígio profissional, posto que seu conhecimento não possui nenhum valor de acordo com os parâmetros acadêmicos. Nóvoa afirma ainda que essa característica leva a um paradoxo, pois ao mesmo tempo em que se percebe a desvalorização profissional, ainda impera um discurso no qual os professores aparecem como elementos fundamentais para uma sociedade do conhecimento. O autor ainda afirma que

Os professores nunca viram o seu saber específico devidamente reconhecido. Mesmo que se reitere a importância de sua missão, a tendência é considerar sempre que lhes basta dominar bem a sua matéria de ensino e ter uma certa aptidão para a comunicação, para o trabalho com os alunos. O resto não é indispensável. (NÓVOA, 2002, p. 227).

Liston e Zeichner (1997) fazem uma crítica a esse sistema de formação de professores que promove a dicotomia pesquisa e ensino. Segundo eles, na academia o problema está relacionado à produção do conhecimento dentro dos limites de suas disciplinas, enquanto que os professores da Educação Básica são vistos como destituídos do direito de realizar a produção do conhecimento, ficando limitados com as necessidades constantes de satisfazer suas demandas práticas impostas pela sala de aula.

Desse modo, percebemos claramente a dicotomia existente entre aqueles que são entendidos como os intelectuais presentes na academia e os professores da Educação Básica. Aqueles têm o trabalho voltado para a pesquisa e produção do conhecimento, enquanto estes são considerados reprodutores do conhecimento cientificamente elaborado. 
Liston e Zeichner (1997) acreditam que os professores estão criando saberes constantemente, assim todas as estratégias que constroem no cotidiano de suas práticas, apresentam teorias sobre a maneira de compreender os valores educacionais. Para eles as teorias construídas pelos professores são teorias tanto quanto aquelas produzidas nas universidades e, portanto, devem ser consideradas. Esses teóricos acreditam que a experiência docente é produtora de conhecimento, por meio de uma sistematização, que passa por uma postura crítica do educador sobre suas experiências, ou seja, Liston e Zeichner consideram a prática profissional como práxis.

Existe uma marcada diferença entre a produção de conhecimentos e sua aplicação, assim como entre os papeis respectivos de produtores e usuários. Se afirma, em geral, que os investigadores produzem conhecimentos que podem ser utilizados pelos professores e administradores das escolas. Por outro lado, há uma postura alternativa que sustenta que os profissionais produzem conhecimentos úteis que dependem do contexto, são particularistas e estão sempre vinculados com valores sociais, pessoais e educativos específicos. Nessa perspectiva, 0 conhecimento útil é quase sempre conhecimento extraído da ação e reflexão práticas sobre a ação prática. (LISTON e ZEICHNER, 1997, p. 145).

Segundo Perrenoud (2002), a profissionalização do ofício do professor aconteceu como consequência de uma evolução, resultado de um processo que envolve tanto a formação inicial quanto a continuada. A partir do século XX a docência, relacionada até então apenas com os saberes a serem ensinados, passou a ser entendida como campo de domínios mais amplos, como o teórico e o prático dos processos de ensino e de aprendizagem.

A formação, inicial ou a continuada, embora não seja a única maneira de promover uma profissionalização do ofício do professor, permanece como uma das principais maneiras de promover o seu reconhecimento. De acordo com Perrenoud (2002, p. 13) "a autonomia e a responsabilidade de um profissional dependem de uma grande capacidade de refletir em e sobre sua ação", por isso ele afirma que o profissional reflexivo é fundamental no que se refere à especialização no trabalho. Nesse aspecto, o estudo sobre a práxis dos professores e suas apresentações/representações autobiográficas são o ponto central deste estudo.

Desde o processo de redemocratização ocorrido no Brasil em meados dos anos 1980, após 21 anos de ditadura, as reflexões sobre o papel dos professores enquanto pesquisadores se desenvolveram de modo mais aprofundado. Especificamente no campo do 
ensino de História fez-se presente a necessidade de compreender o papel dos professores e sua relação com o conhecimento escolarizado. Nesse contexto Fonseca afirma que

As lutas pela extinção dos cursos de licenciatura curta em estudos sociais durante os anos 70 e 80 do século XX, o movimento internacional de revisão e ampliação da produção historiográfica, o processo de redemocratização do Brasil, os movimentos sociais, as mudanças curriculares para o ensino fundamental, médio e universitário fizeram emergir novos dilemas sobre os modelos de formação e a profissionalização do historiador e do professor de história (FONSECA, 1995, p. 61).

Foi a partir deste momento que as discussões sobre o papel dos professores enquanto pesquisadores tornou-se objeto de pesquisas acadêmicas. Esse conceito se baseava na ideia de que ao professor cabia adotar práticas de investigação acerca do seu próprio campo de atuação, atitude que permitiria ao profissional da docência tomar consciência da sua própria profissão, assumindo a postura de sujeito pensante e de profissional entendido enquanto intelectual.

Para compreender como esse conceito vem sendo inserido é preciso conhecer a sua construção a partir da Lei de Diretrizes e Bases da Educação (LDB) - 9394/1996. O Projeto de Lei de Diretrizes e Bases foi proposto, ainda na década de 1960, pelo então Ministro da Educação Clemente Mariani, que resultou na primeira Lei de Diretrizes e Bases no 4.024/61, sancionada em 20 de dezembro de 1961. Modificada por emendas e artigos, novas versões foram apresentadas pela lei 5.692/71 e posteriormente, substituída pela atual LDB 9.394/96.

Esta lei, que foi assinada em dezembro de 1996, parte do pressuposto de que a Educação e dever do Estado e desde a sua assinatura existe um intenso debate visando a garantia de um ensino público de qualidade dentro de padrões mínimos, que devem ser atendidos em todas as unidades da federação.

A referida LDB, no seu artigo 67, postula que

Os sistemas de ensino promoverão a valorização dos profissionais da educação, [...]

II - aperfeiçoamento profissional continuado [...]

$\mathrm{V}$ - período reservado a estudos, planejamento e avaliação, incluído na carga de trabalho. (BRASIL, 1996).

Desde 2004 o MEC procurou desenvolver programas voltados a formação inicial e continuada dos professores, visando responder as necessidades objetivas da escola básica no Brasil. Um dos programas voltados a formação continuada de professores é a Rede 
Nacional de Formação Continuada. Outras iniciativas vêm a partir do "apoio a cursos de segunda licenciatura, além de discussões sobre novas bases para a formação inicial e continuada, cursos experimentais de formação de professores direcionados à educação do campo e indígena". (Parecer 02, 2015, p. 6).

O Parecer 02 (2015) do Conselho Pleno (CP) do Conselho Nacional de Educação (CNE), publicado no Diário Oficial da União (DOU) em 25 de junho de 2015, estabelece as Diretrizes Curriculares Nacionais para a Formação Inicial e Continuada dos Profissionais do Magistério da Educação Básica, destaca fundamentalmente

a necessária unidade teoria e prática, na ação docente e principio educativo central da formação de professores. As pesquisas recentes no campo do ensino de História têm apontado que aprendizagens históricas significativas dependem, dentre outros fatores, de uma intrínseca relação teoria e prática. (GERMINARI, GONÇALVES, 2016, p. 62-63)

Não é possível pensar em formar bons professores de História que não sejam também historiadores competentes, pois somente com o conhecimento profundo da epistemologia da ciência de referência é possível desenvolver um trabalho pedagógico que faça com que o aluno desenvolva consciência histórica e pensamento crítico para conhecer o passado, analisar o presente e perspectivar o futuro.

\section{O professor e as discussões atuais sobre o ensino da história}

Apesar das discussões sistemáticas envolvendo a necessidade de se adotar a pesquisa como requisito para o ensino de História, a Educação Básica ainda é refém de uma ideia que situa o ensino de História no campo da aplicação do conhecimento produzido pela Universidade, ou seja, o conhecimento histórico escolarizado ainda se apresenta como reprodução do que os profissionais da Universidade vêm produzindo.

Como afirma Theobald (2007, p. 51) "a prática educativa escolar tem sido abordada muito mais pela sua natureza de transmissão de conhecimentos - ensino, e não como produtora de conhecimentos - pesquisa".

Tendo como ponto de partida a importância que recai sobre a formação inicial e continuada de professores de História e a relação teoria e prática, assentada sobre o uso da pesquisa sobre sua própria prática, a Educação Histórica se apresenta como metodologia que pode auxiliar o desenvolvimento do trabalho pedagógico que parte do passado do professor e dos alunos para o desenvolvimento da consciência histórica. 
Ao repensar as ações metodológicas e as concepções do ensino da disciplina na Inglaterra dos anos 70, a New History passou a conceber a História escolarizada de uma nova maneira, a partir da qual tanto os estudantes eram entendidos como agentes de sua própria formação, com No Brasil, compreendem-se como Educação Básica as três etapas da escolarização que tem, no Estado, o seu gestor: a Educação Infantil, o Ensino Fundamental e - Ensino Médio. A Educação Básica e deve seguir as normas estabelecidas pela chamada LDBEN (Lei de Diretrizes e Bases da Educação Nacional/1996).

De acordo com essa perspectiva da Educação Histórica, não interessa apenas saber História, mas o uso que se faz dela. É o que Lee identifica como sendo a Literacia Histórica, ou seja, a capacidade de "ler o mundo historicamente". (LEE, 2006). Essa capacidade deve ser desenvolvida tanto por alunos quanto professores, sobretudo a partir da ideia de orientação temporal, ou seja, através da "consciência história", ideia que dialoga com o conceito desenvolvido por Rüsen (2001), e que se embasa na preocupação com o saber histórico, com o pensar historicamente de crianças e jovens, bem como dos professores. (SOBANSKI, 2008).

Ao entender a importância do conhecimento da epistemologia da História, apoiando-se nos estudos de Rüsen, e nas reflexões sobre o modo como esses estudos podem modificar a forma de pensar dos professores de História, bem como de suas aulas, a Educação Histórica tem servido como importante suporte para a realização de investigações que apontam para a compreensão dos professores da Educação Básica. De acordo com Rüsen

no estudo de História, a teoria desempenha um importante papel na profissionalização didática dos historiadores. Esse papel consiste em transmitir aos historiadores em formação uma concepção sólida da especialidade profissional de sua ciência. (RÜSEN, 2001, p.38)

Dessa forma, cabe ressaltar que os professores passam a ser entendidos, cada vez mais, como pesquisadores de sua prática, numa incessante busca em conciliar a teoria e a prática educativas. Nesse sentido, é muito importante considerar o que os professores sabem sobre a natureza da sua disciplina e sobre seu ensino. Nesse processo, os professores precisam ser entendidos como investigadores. Nessa perspectiva, Schmidt (2015) utiliza o conceito de historiador professor e afirma que para a formação desse profissional 
requeria-se à formação do historiador professor, um sólido conteúdo científico, um consistente preparo de pesquisador, teórico e prático, envolvendo o compromisso político de transformá-lo significativamente na relação com a práxis, não com a prática em si mesma, mas com o mundo real, concreto e histórico de si mesmo e dos seus alunos. (SCHMIDT, 2015. p. 517-528)

Somando-se a essa necessidade de repensar a formação dos professores de História, a Educação Histórica, pautada na teoria do historiador e filósofo alemão Jörn Rüsen, vem colaborar com novas discussões sobre o ensino e a aprendizagem de História e, de forma imprescindível, sobre as ações dos professores-pesquisadores, sobretudo no que se refere ao desenvolvimento da consciência história dos estudantes.

A construção do conhecimento histórico a partir da vivência de professores

O professor é um dos sujeitos presentes na cultura escolar e as relações que estabelece com o conhecimento epistemológico da disciplina de referência também são influenciadas por seu passado, sua formação e suas experiencias porque, de acordo com Forquin,

ninguém pode ensinar verdadeiramente se não ensina alguma coisa que seja verdadeira ou válida a seus próprios olhos. Esta noção do valor intrínseco da coisa ensinada [...] está no próprio centro daquilo que constitui a especificidade da intenção docente como projeto de comunicação formadora. (FOURQUIN, 1993, p. 9)

Nesse sentido, é muito importante considerar o que os professores sabem sobre a natureza da sua disciplina e sobre seu ensino. Nesse processo, os professores precisam ser entendidos como investigadores.

Nessa perspectiva, Schmidt (2015) utiliza o conceito de historiador professor e afirma que para a formação desse profissional

requeria-se à formação do historiador professor, um sólido conteúdo científico, um consistente preparo de pesquisador, teórico e prático, envolvendo o compromisso político de transformá-lo significativamente na relação com a práxis, não com a prática em si mesma, mas com o mundo real, concreto e histórico de si mesmo e dos seus alunos. (SCHMIDT, 2015, p. 517-528)

Somando-se a essa necessidade de repensar a formação dos professores de História, a Educação Histórica, pautada na teoria do historiador e filósofo alemão Jörn Rüsen, vem colaborar com novas discussões sobre o ensino e a aprendizagem de História e, 
de forma imprescindível, sobre as ações dos professores-pesquisadores, sobretudo no que se refere ao desenvolvimento da consciência história dos estudantes.

O professor, ao desenvolver a disciplina de História em sala de aula necessita conhecimento teórico e metodológico. E o que permite dar significado aos acontecimentos históricos são as suas "interrelações" com outros fatos e processos do passado e do presente. A significância de um acontecimento passado e sua escolha para o desenvolvimento do trabalho pedagógico se dá por uma escolha moral, pelas relações com outros eventos e sujeitos e com a interpretação da "sua importância para o presente", além dos imperativos curriculares. Para Peter Seixas, (1994, p. 104) "a História é a disciplina através da qual organizamos os vestígios e relatos do passado de uma forma significativa para nós no presente".

Rüsen (2001, 2007) denomina de operações mentais da consciência histórica: a experiência do sujeito em relação a múltiplas temporalidades, a interpretação, que está baseada nas teorias e explicações históricas que fundamentam os valores e significados a partir de inferências históricas e a orientação que permite aos sujeitos expressarem as relações entre o passado - presente - futuro, sendo capaz de construir suas identidades a partir do reconhecimento do outro e do passado que está presente no presente do sujeito. Perante o fato da impossibilidade de confrontação com o passado em si mesmo, resta a possibilidade de organizar coerentemente os traços e relatos do passado, para a compreensão da situação do sujeito no tempo. (SANTOS, 2013, p. 62-63)

Mas, se por um lado o passado está em todo o lugar como afirmam Seixas (1998) e Lowenthal (1998), em outro sentido o passado também está irremediavelmente desaparecido. Então não existe nunca uma confrontação direta com o próprio passado, mas com representações do mesmo. Lowenthal $(1989,1998)$ afirma que o conhecimento do passado não ocorre de forma direta e sim através de inferências que são dadas através de vestígios que este passado deixou no presente. O modo que os professores de história reconhecem o passado dão indicativos de como eles compreendem e desenvolvem o trabalho com a ciência de referência. Santos (2013) apresenta, em cinco categorias os modos como os professores de História entendem o passado, que vai desde o passado estático, como uma imagem imóvel do que aconteceu até o conceito de passado utilizado para orientação no tempo e perspectiva de futuro. 
O livro O Ensino de História: revisão urgente, de 1987, organizado por Conceição Cabrini afirma que existem duas condições indispensáveis para os professores atuarem em sala de aula na Educação Básica: em primeiro lugar é necessário dominar o processo de ensino e de aprendizagem e, sobretudo, é preciso ter clareza da concepção de História que utilizam.

O novo enfoque passou a ser abordado ainda mais a partir do final dos anos 80 e início dos anos 90 com outras publicações, como nos dossiês da Revista Brasileira de História, todos dedicados ao ensino de História. Essas produções demonstravam como, naquele momento, o ensino passava a se tornar um importante viés de investigação no campo da História.

Entre as "grandes novidades" daquele contexto inseria-se a utilização das fontes documentais e dos recursos tecnológicos como elementos fundamentais para a aprendizagem histórica em sala de aula. Embora a ideia do professor como pesquisador não esteja evidente nessa perspectiva, o seu papel como produtor de conhecimento, uma vez que precisava dominar os conteúdos e, de certo modo, a sua ciência de referência, começava a ser entendido como fundamental na relação ensino-aprendizagem de História.

Foi a partir da reflexão sobre a relação entre a produção e a reprodução do conhecimento que os autores do livro $O$ Ensino de História: revisão urgente criaram um conceito que denominaram de "discurso competente". Segundo esse conceito há uma cadeia de dominação sobre o saber utilizado, desde a Academia até a sua reprodução nas salas de aula da Educação Básica. Desse modo, o professor da Educação Básica, ao mesmo tempo em que possui poder sobre o conhecimento, pois tem domínio sobre os conteúdos a serem trabalhados, escolhe os materiais e recursos utilizados em suas aulas, além de exercer poder sobre os estudantes, também sofre com a interferência do conhecimento histórico que é reproduzido seja pela Academia, pelos currículos ou pelos livros-didáticos. Assim, o professor

exerce essa dominação, mas também a sofre, por sua situação de dependência em relação ao 'saber produzido pela academia', em relação às suas condições de trabalho, em relação à situação estrutural do ensino, em relação à cobrança de seu papel profissional, pelos alunos, pais, diretores e instituições de ensino, ou seja, em relação à pressão vinda dos mais diferentes setores da sociedade". (SILVA, 1984, p. 20) 
Como uma forma de resolver esse problema se propunha que professores de História da Educação Básica procurassem promover a reflexão ao elaborar suas aulas, conciliando a teoria com a prática. Para tanto se sugeria que os professores deveriam dominar o processo do conhecimento histórico o que pode ser entendido como uma proposta de desenvolvimento de pesquisa e produção do conhecimento nas escolas da Educação Básica. Em posse desse domínio de sua ciência de referência elaborariam aulas nas quais os estudantes também passariam a tomar contato com os "caminhos da produção e da relação crítica com o saber".

Em outras palavras: o professor de História precisa ser alguém que entenda de História, não no sentido de que saiba tudo o que aconteceu com a humanidade, mas que saiba como a História é produzida e que consiga ter uma visão crítica do trabalho histórico existente. (CABRINI, 1987, p. 23)

Uma experiência que exemplifica esse contato entre professores Educação Básica e o conhecimento histórico como princípio para desenvolvimento de suas aulas foi o curso realizado em 2013, numa parceria entre o Laboratório de Pesquisa em Educação Histórica (LAPEDUH) da UFPR e a Secretaria de Estado da Educação (SEED/PR). Com uma ida ao Arquivo Público do Paraná, esses professores deveriam selecionar uma fonte primária com a qual fariam a relação de um conteúdo, de acordo com uma série previamente estabelecida. O objetivo era construir, a partir do conteúdo, uma relação entre a fonte e a História do Paraná, num exercício de leitura da História e de construção do conhecimento, uma vez que este não se encontra encerrado em nenhum material didático.

Com essa fonte primária selecionada, os professores foram conduzidos, por meio da teoria desenvolvida por autores como Rüsen, Ashby, Lee, Barca e Schmidt, a trabalhar um conteúdo substantivo específico da História do Paraná e investigar a forma como seus alunos compreendem e produzem uma determinada narrativa histórica. Rüsen (2007) denomina de Conceitos históricos aqueles conceitos que são próprios da História, como Revolução Francesa. Lee (2005), por sua vez, os denomina de Conceitos substantivos.

São eles, portanto, os conteúdos curriculares que fazem parte do ensino de História. Ao selecionar as fontes que seriam utilizadas em sua pesquisa, os professores puderam perceber que

se a investigação histórica deve estar no centro do currículo de História e ser reconhecida como um empreendimento sério nas aulas de História, então o principal para o currículo e para o empreendimento deve ser o 
desenvolvimento dos conceitos de evidência histórica pelos alunos. (ASHBY, 2006, p. 153-154)

Para que esses professores pudessem desenvolver a sua pesquisa, primeiramente precisaram retomar o conceito de fonte histórica, bem como a ideia de que a ida ao passado só tem sentido se a "experiência do passado é interpretada e, com ela, as mudanças temporais do presente são entendidas e o futuro, esperado". (RÜSEN, 2012, p. 42). Com as fontes é possível ir até uma determinada parte do passado realizando uma investigação sistematizada, por isso a necessidade de selecionar um conteúdo próprio da História.

Desse modo, esses professores também investigaram a sua própria prática, sendo responsáveis pela produção de um conhecimento específico, além de analisar como acontece a aprendizagem de seus alunos.

Ainda com o objetivo de refletir sobre a própria prática, esses professores participantes do curso foram convidados a responder qual era o conceito de pesquisa e qual a sua importância para as aulas de História.

\begin{tabular}{|c|l|}
\hline \multicolumn{2}{|c|}{ Narrativas de professores: ideias sobre de pesquisa a partir de suas experiências } \\
\hline $\begin{array}{c}\text { Professora } \\
\text { Simone }\end{array}$ & Separação entre professor e historiador/pesquisador. \\
\hline $\begin{array}{c}\text { Professor } \\
\text { Edson }\end{array}$ & $\begin{array}{l}\text { Resgate da experiência dos estudantes e ampliação das informações por } \\
\text { parte do professor. }\end{array}$ \\
\hline $\begin{array}{c}\text { Professora } \\
\text { Lucinéa }\end{array}$ & $\begin{array}{l}\text { Forma como o aluno aprende: usar a pesquisa como parâmetro para a } \\
\text { aprendizagem. }\end{array}$ \\
\hline $\begin{array}{c}\text { Professora } \\
\text { Cynthia }\end{array}$ & Construir/solidificar o conteúdo com base na historiografia. \\
\hline $\begin{array}{c}\text { Professora } \\
\text { Valéria }\end{array}$ & Domínio de um conhecimento/conteúdo específico. \\
\hline $\begin{array}{c}\text { Professor } \\
\text { Cleber }\end{array}$ & $\begin{array}{l}\text { Construir a História e registrá-la (teoria e prática). Existe uma diferença entre } \\
\text { a pesquisa da licenciatura e a outra para o bacharelado. }\end{array}$ \\
\hline
\end{tabular}

\section{Quadro 1}

Percebe-se, com essas respostas, que ainda existe certo conflito entre o que os professores entendem enquanto pesquisa e a forma como pensam trabalhar com essa metodologia própria da ciência de referência. A professora Simone, por exemplo, relembra a velha dicotomia existente na formação dos cursos de História reforçando a ideia de que existem aqueles profissionais que fazem parte do mundo acadêmico, dominando os recursos e a prática da pesquisa e aqueles, saídos da licenciatura, os professores, entendidos

\footnotetext{
${ }^{1}$ Todos os nomes dos professores aqui mencionados são fictícios, para garantia da confidencialidade do sujeito de pesquisa.
} 
exclusivamente como reprodutores do conhecimento produzido pela academia. Da mesma forma, o professor Cleber relembra essa dicotomia e aponta a necessidade de articulação entre a teoria e a prática, atitude tão cara à Educação Histórica.

A professora Cynthia aponta a importância de situar a disciplina na ciência de referência, pois afirma que é preciso "solidificar o conteúdo com base na historiografia". De acordo com o professor Edson, a pesquisa é entendida como o momento de estudo por parte de estudantes e professores, sendo por meio dela que os profissionais da História vão se apropriar da produção historiográfica. É possível que, nesse momento, relembre-se de parte de sua experiência durante a graduação, quando teve contato com a historiografia, que deveria orientar seu trabalho. Segundo ele, não é necessário que o professor domine todo o conhecimento, mas que deva realizar a pesquisa do que será estudado junto com seus alunos. Esse mesmo professor afirma que, no que se refere à pesquisa, é preciso perceber que não existe uma mesma metodologia para professores e estudantes, ou seja, para o professor, enquanto produtor de conhecimento, a pesquisa deve ser realizada de uma maneira específica, diferente daquela entendida como processo de aprendizagem dos estudantes. A pesquisa enquanto parâmetro de avaliação foi a resposta dada pela professora Lucinéa. De certo modo, nessa resposta, é possível perceber que para essa professora a literacia histórica se apresenta no processo da pesquisa, na relação dos estudantes com as fontes históricas ao interpretá-las, tendo contato com outros passados e se orientando temporalmente. De acordo com a especificidade de cada um desses professores pesquisadores, foi possível perceber procedimentos diferentes no momento de recolher esses conhecimentos prévios, atividade que não era comum na prática da maioria dos envolvidos.

\section{Algumas considerações}

Quando uma narrativa é construída, vestígios do passado que estão no presente são utilizados para responder a uma carência de orientação para a vida prática. Ao se voltar para o passado, o sujeito busca resolver questões postas pelo seu presente com vistas a projetar uma expectativa de futuro em uma atividade de compreensão que liga presente, passado e futuro respondendo as suas necessidades de compreensão histórica.

Lowenthal $(1989,1998)$ afirma que o conhecimento do passado não ocorre de forma direta e sim através de inferências que são dadas através de vestígios que este 
passado deixou no presente. Desta forma, ao reconhecer que o conhecimento anterior do professor, seja de sua vida cotidiana ou de sua formação inicial ou continuada, faz parte do processo de construção do conhecimento que ele desenvolve junto aos seus alunos, é possível desenvolver sua metodologia de forma a levar em conta esse conhecimento na sua prática pedagógica. Todos os vestígios do passado trazidos pela experiencia dos professores, na relação deles com o passado e os seus objetos e memórias auxiliam na construção da metodologia a ser utilizada em sala de aula e que leva em conta a epistemologia da ciência de referência, os aportes pedagógicos e as experiencias pessoais para a construção do conhecimento histórico significativo para os alunos.

A título de término, pode-se afirmar como Coughlin, que é impossível conhecer o ensino sem o professor, a prática sem o praticante e o conhecimento separado do conhecedor (COUGHLIN, 2002, p. 35).

\section{REFERÊNCIAS BIBLIOGRÁFICAS}

ARROYO, M. G. Revendo os vínculos entre trabalho e educação: elementos materiais da formação humana. In: SILVA, T. T. (org.) Trabalho, educação e prática social. Porto Alegre: Artes Médicas, 1991, p. 163-216.

ASHBY, R. Desenvolvendo um conceito de evidência histórica: as ideias dos estudantes sobre testar afirmações factuais singulares. Educar em Revista, Curitiba, n. 164, 2006, Edição especial, p. 151-170.

CABRINI, C. O Ensino de História: revisão urgente. São Paulo: Brasiliense, 1987.

CAINELLI, M. \& SCHMIDT, M. A. Introdução: percursos das pesquisas em educação histórica: Brasil e Portugal. In M. CAINELLI \& M. SCHMIDT (Org.). Educação histórica: teoria e pesquisa. ljuí: Ed. Unijuí, 2011.

CONSTITUIÇÃO da República Federativa do Brasil de 1988. (1988). Brasília. Disponível em: <http://www.planalto.gov.br/ccivil_03/Constituicao/Constituicao.htm>. Acesso em: 02 nov. 2016.

COUGHLIN, M. What Counts and Why? Exploring Historical Significance as Constructed by High School United States History Teachers. 145 f. Tese. (doutorado em Educação) - Lynch Graduate School of Education, Boston College, Boston, 2002.

DECRETO n. 8.752, de 09 de maio de 2016 (2016). Dispõe sobre a Política Nacional de Formação dos Profissionais da Educação Básica. Brasília, DF. Disponível em: http://www.planalto.gov.br/ccivil_03/_Ato2015-2018/2016/ Decreto/D8752.htm. Acesso em: 2 de novembro, 2016.

FONSECA, S. G. Caminhos da história ensinada. Campinas: Papirus. 1995.

FONSECA, S. G. Didática e prática de ensino de história: experiências, reflexões e aprendizados. Campinas, SP: Papirus, 2003. 
FORQUIN, J. Escola e cultura: as bases sociais e epistemológicas do conhecimento escolar. Porto Alegre: Artes Médicas, 1993.

GERMINARI, G. D.; GONÇALVES, R. C. As políticas educacionais e formação do professor de história no Brasil: Desafios contemporâneos. Interacções, Lisboa, n. 40, 2016, p. 55-69.

LEE, P. Em direção a um conceito de literacia histórica: a escolha de recursos na aula de História. Educar em Revista, Curitiba, n. 164, 2006, Edição especial, p. 131-150.

LEE, P. Putting principles into practice: understanding history. In: BRANSFORD, J. D.; DONOVAN, M. S. (Eds.). How students learn: history, math and science in the classroom. Washington, DC: National Academy Press. Tradução de Clarice Raimundo. 2005.

LEI 9.394, de 20 de dezembro de 1996. Estabelece as Diretrizes e Bases da Educação Nacional. Rio de Janeiro: DP\&A. 2002.

LEI n. 13.005, de 25 de junho de 2014 (2014). Aprova o Plano Nacional de Educação - PNE e dá outras providências. Brasília, DF. Disponível em: https://www.planalto.gov.br/ccivil_03/_ato20112014/2014/lei/l13005.htm. Acesso em: 02 nov. 2016.

LISTON, D. P. y ZEICHNER, K. M. Formación del profesorado y condiciones de la escolarización. Madrid: Morata, 1997.

LOWENTHAL, D. Como conhecemos o passado. Projeto História: Trabalhos da Memória. São Paulo: PUC, n. 17, 1989.

LOWENTHAL, D. El pasado es un país extraño. Madri: Akal, 1998.

NÓVOA, A. Os professores e o "novo" espaço público da educação. In: TARDIF, M.; LESSARD, C. O ofício do professor. História, perspectivas e desafios internacionais. São Paulo: Vozes, 2009.

NUNES, C. M. F. Saberes docentes e formação de professores: um breve panorama da pesquisa brasileira. Educação e Sociedade, 22 (74), 2001, p. 27-42.

PARECER CNE/CP n. 2, de 09 de junho de 2015 (2015). Diretrizes Curriculares Nacionais para a Formação Inicial e Continuada dos Profissionais do Magistério da Educação Básica. Brasília, DF. Disponível em: http://pronacampo.mec.gov.br/images/pdf/parecer_cne_cp_2_2015_aprovado_9 junho_2015.pdf. Acesso em: 02 nov. 2016.

PERRENOUD, P. A Prática Reflexiva no Ofício do Professor: Profissionalização e razão pedagógica. Porto Alegre: Artmed Editora, 2002.

RÜSEN, J. Aprendizagem histórica: fundamentos e paradigmas. Curitiba: W.A. Editores, 2012.

RÜSEN, J. História viva. Teoria da História III: formas e funções do conhecimento histórico. Brasília: Editora Universidade de Brasília, 2007.

RÜSEN, J. Razão histórica. Teoria da História: os fundamentos da ciência histórica. Brasília: Editora Universidade de Brasília, 2001.

SANTOS, R. C. G. P. A significância de conceito de passado para professores de história do ensino médio. Tese (Educação) UFPR. Curitiba: 2013. 262 f. 
SCHEIBE, L.; BAZZO, V. L. Formação de professores da educação básica no ensino superior: diretrizes curriculares pós 1996. Revista Internacional de Educação Superior. 2 (2), 2016, p. 241-256.

SCHEIBE. L. Educação básica no Brasil: expansão e qualidade. Retratos da Escola, 8 (14), 2014, p. 101114.

SCHMIDT, M. A.; CAINELLI, M. Ensinar histórica. São Paulo: Scipione. 2004.

SEIXAS, P. Conceptualizing the Growth of Historical Understanding. In: OLSON, D.R.; TORRENCE, N. The Handbook of Education and Human Development. London: Blackwell, 1998. 816 p. p. 765-783.

SEIXAS, P. Students' Understanding of Historical Significance. Theory and Research in Social Education, Washington, v. 22, n. 3, 1994, p. 281-304.

SCHMIDT, M. A. Formação do professor de História no Brasil: embates e dilaceramentos em tempos de desassossego. Santa Maria, v. 40, n. 3, set./dez. 2015, p. 517-528.

SILVA, M. (org.) Repensando a História. Rio de Janeiro: Marco Zero, 1984.

SOBANSKI, A. Q. Formação dos professores de história: educação histórica, pesquisa e produção de conhecimento. História \& Ensino, 2014, 20 ( 2), p. 129-142.

SOBANSKI, A. Q. Como os professores e jovens estudantes do Brasil e de Portugal se relacionam com a ideia de África. Dissertação. (Mestrado), UFPR. Curitiba, 2008.

SOBANSKI, A. Q. Formação de professores de história: educação histórica, pesquisa e produção de conhecimento. Tese. (Doutorado), UFPR. Curitiba, 2017.

THEOBALD, H. A experiência de professores com ideias históricas: o caso do "Grupo Araucária". Mestrado, UFPR. Curitiba, 2007. 